\title{
Spontaneous reporting of adverse drug reaction among health professionals in Ghana
}

\author{
Morrison Asiamah', Kwadwo Owusu Akuffo ${ }^{2}$, Pricillia Nortey ${ }^{1}$, Nina Donkor ${ }^{3}$ and Anthony Danso-Appiah ${ }^{1,4^{*}}$ (D)
}

\begin{abstract}
Background: Spontaneous reporting of adverse drug reactions (ADR) is an effective means of ensuring postmarketing surveillance of drugs, and health professionals play a cardinal role through voluntary reporting of ADR. However, the pharmacovigilance system in Ghana is plagued with under-reporting issues, which is of public health concern.

Method: A questionnaire-based cross-sectional study involving 268 health professionals at Kpone-Katamanso District was carried out. Data on spontaneous reporting of ADR, demographics of participants, knowledge, and attitudes of professionals towards reporting and factors that may influence ADR reporting were collected. Logistic regression models were used to examine the association of the independent variables with spontaneous reporting of ADR.
\end{abstract}

Result: Overall, $77.6 \%$ (208) of the 268 respondents had observed ADR; however, only $17.3 \%$ of the respondents had ever reported an ADR to the Ghana FDA. Health professionals who had average knowledge on spontaneous reporting of ADR were 51.9\%, while $30.3 \%$ had good knowledge of spontaneous reporting of ADR. After adjustment on potential confounding variables (Knowledge, Feedback from FDA, Uncertainty about cause of ADR, Severity of $A D R)$, Age $(A O R=2.26,95 \% C l=1.25-4.10)$, Fear of Legal Consequences $(A O R=0.15,95 \% C l=0.41-0.51)$, Time Constraint $(A O R=0.3,95 \% \mathrm{Cl}=0.10-0.91)$, Pharmacovigilance training $(A O R=18.78,95 \% \mathrm{Cl}=5.46-64.59)$ and Unavailability of Reporting form ( $\mathrm{AOR}=0.28,95 \% \mathrm{Cl}=0.09-0.88$ ) were found to be significantly associated spontaneous reporting of ADR.

Conclusion: The proportion of health professionals in the Kpone- Katamanso District who spontaneously reported observed ADR was low though they had average knowledge about ADR reporting. This underscores the need for a policy to be implemented that makes spontaneous reporting of adverse drug reaction mandatory for health professionals.

Keywords: Adverse drug reaction, Reporting, Health professionals, Ghana

\footnotetext{
*Correspondence: adanso-appiah@ug.edu.gh; tdappiah@yahoo.co.uk

'Department of Epidemiology and Disease Control, School of Public Health,

College of Health Sciences, University of Ghana, Legon, Ghana

${ }^{4}$ University of Ghana Centre for Evidence Synthesis and Policy, School of

Public Health, University of Ghana, Legon, Accra, Ghana

Full list of author information is available at the end of the article
}

\section{$\triangle B M C$}

(c) The Author(s). 2021 Open Access This article is licensed under a Creative Commons Attribution 4.0 International License, which permits use, sharing, adaptation, distribution and reproduction in any medium or format, as long as you give appropriate credit to the original author(s) and the source, provide a link to the Creative Commons licence, and indicate if changes were made. The images or other third party material in this article are included in the article's Creative Commons licence, unless indicated otherwise in a credit line to the material. If material is not included in the article's Creative Commons licence and your intended use is not permitted by statutory regulation or exceeds the permitted use, you will need to obtain permission directly from the copyright holder. To view a copy of this licence, visit http://creativecommons.org/licenses/by/4.0/ The Creative Commons Public Domain Dedication waiver (http://creativecommons.org/publicdomain/zero/1.0/) applies to the data made available in this article, unless otherwise stated in a credit line to the data. 


\section{Background}

Drugs play a significant role in disease management. However, when administered within their therapeutic dosing schedule, drugs can lead to unwanted effects, which may pose threats to the life of patients [1]. These unwanted effects are referred to as adverse drug reactions (ADR) - undesirable effects that may occur as part of a drug's pharmacological action [2]. The economic and social impact of ADR is huge and cannot be overlooked [3]. ADR has been projected to be one of the leading causes of morbidity and mortality across all age groups and hospital admissions [4, 5].

In order to reduce the incidence of ADR, the safety of drugs are ascertained through various phases of clinical trials prior to their approval on the market [6]. However, the safety reports from these clinical trials are collated from strictly controlled conditions which may be subject to bias due to strict inclusion and exclusion criteria and limited time. For example, the effects of these drugs are often not studied on some members of the population such as children under 5 years, pregnant women and very old people; thus, yielding outcomes that may not be perfectly generalizable [7].

Spontaneous reporting of ADR is the cornerstone of pharmacovigilance that helps address safety concerns after drug administration [8]. It provides information from real-life clinical practice as opposed to that of clinical trials where some subjects are excluded and the safety of the drug is studied under a limited time [3, 9]. Spontaneous reporting is an inexpensive, flexible and very effective method of collecting information whereby health professionals voluntarily submit case reports of ADR; pharmaceutical companies or consumers to the national pharmacovigilance centres for evaluation in order to mitigate the impact of ADR on society [9].

For a pharmacovigilance system to effectively monitor ADR of both existing and newly introduced drugs, the World Health Organisation (WHO) recommends that the spontaneous reporting of adverse effects should be more than 200 reported cases per 1,000,000 population [10]. In 2019, the National Pharmacovigilance Center of Ghana recorded 2236 reported cases of adverse drug cases representing about 75 reported cases per 1,000,000 population of Ghanaians [10]. Though an improvement in reported cases from previous years, the reporting rates have constantly been below the WHO standard (Fig. 1). Underreporting of ADR is a big challenge in pharmacovigilance, especially in countries that utilize the spontaneous or voluntary ADR reporting system such as Ghana $[11,12]$.

Per WHO recommendations, Kpone-Katamanso district, with a huge population and several health facilities, should report a minimum of 22 cases of ADR a year. However, the number of ADR reported, and the factors

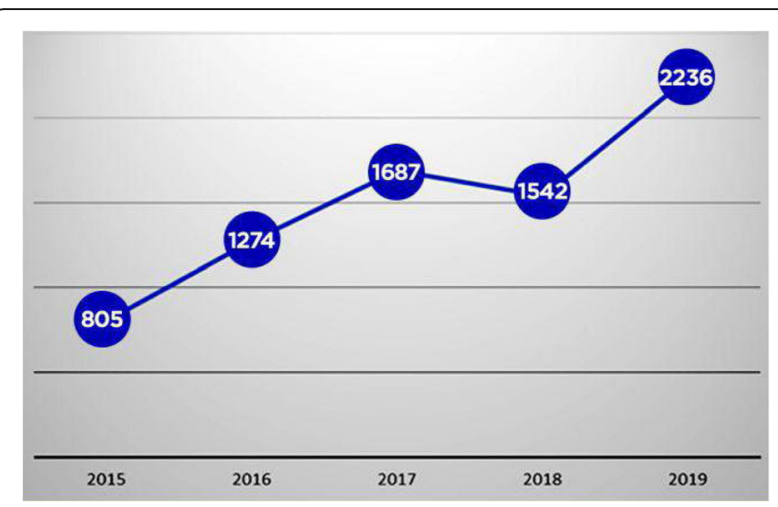

Fig. 1 Trend in adverse event reporting in Ghana from 2015 to 2019

influencing reporting are largely unknown. Several studies have identified attitudes such as complacency or doubt about the causal relationship of the event with the drug, procrastination and indifference to report, and apprehension about the legal consequences of reporting $\mathrm{ADR}$ as attitudes negatively affecting spontaneous reporting [13]. An assurance of confidentiality of the reporter's identity, legal protection and incentives for reporting have been identified to promote spontaneous reporting [14]. Additionally, indifference, diffidence, complacency, ignorance, lack of monetary incentives, and personal desire to publish cases have been suggested as predictors of low ADR reporting, to the extent that in some cases, less than $50 \%$ of health professionals showed good attitude towards reporting ADR [15]. Also, the lack of knowledge on how to report an ADR and lack of access to reporting forms are major factors contributing to poor reporting rate [16].

Though health professionals have enough knowledge and are aware of the need to report ADR, smaller proportions spontaneously report ADR [17]. Health system factors that influence spontaneous reporting of ADR include health professionals knowledge, attitude and beliefs [18]. Socio-demographic characteristics of the health professional such as their age, gender, qualification, years of practice, number of patients seen in a day, and marital status also influence spontaneous reporting of ADR [19]. Elsewhere, female health professionals were more likely to report ADR than their male counterparts $[19,20]$. The health professional's age tends to affect reporting rate, which has been consistent across studies from different geographic locations with older and experienced professionals more likely to report an event [19, $21,22]$.

The perennial issue of underreporting ADR in the pharmacovigilance system in Ghana and the consequential increase in mortality, hospitalization, congenital anomaly and economic burden as well as paucity of data influenced our decision to conduct this study in an 
attempt to identify context-specific factors influencing the rate of spontaneous ADR reporting among health professionals. It is anticipated that information obtained from this study would be useful to stakeholders in the formulation of policies and strategies to increase spontaneous reporting of ADR in the country. In Ghana, the Food and Drugs Authority (FDA) is responsible for drug safety issues under the Public Health Act 851 . Thus, the Ghana FDA keeps an ADR data repository. The trend of spontaneous reporting has progressively increased since the country joined the International Medicine Safety Monitoring System in 2001 as the 65th Member State and the 1st in sub-Saharan Africa [23]. The Pharmacovigilance system of reporting in Ghana is such that, at the various health facilities there are mandated Institutional Contact Persons (ICP) who should serve as the link between the Ghana FDA and the health professionals with regards to ADR reporting [24]. Where a patient experiences an ADR, an ADR reporting form (known as the "blue form"), is filled and submitted through the ICP or any health professional at the facility to the regional offices of the Ghana FDA [24]. At the regional offices, there are designated regional Pharmacovigilance officers who receive the report forms, assess the validity of the report and present the report to the national FDA Central Database [23]. Health professionals from a health facility can forward an ADR report directly through the online reporting page of the FDA's website to an International Conference of Harmonization E2B compliant Central Database of the Ghana FDA [24]. The reports received at the headquarters of Ghana FDA are forwarded as an E2B (xml) file [23].

While Health professionals report adverse events voluntarily, Pharmaceutical Manufacturing Companies are mandated to report ADR of their pharmaceutical products to the Ghana FDA. The companies do this through the Qualified Person for Pharmacovigilance (QPPV), a trained individual responsible for reporting all pharmacovigilance for all medicinal products by pharmaceutical companies holding marketing authorizations.

\section{Methods}

\section{Study design}

This study employed an analytical cross-sectional design using a well-structured, pretested, close-response questionnaire to collect data from randomly selected health professionals involved in ADRs reporting in the KponeKatamanso District in Ghana.

\section{Study population and location}

The study population was health professionals in the Kpone-Katamanso District who were directly involved in the diagnosing, dispensing and administering drugs directly to the patients and as such are in the position to report any drug-related reactions of the patient. They included: pharmacists and pharmacy Technicians, physicians and physician assistants, nurses, midwives, and disease control officers working in health facilities in the Kpone-Katamanso District.

The Kpone-Katamanso District was created out of the Tema Metropolitan Assembly in 2012 through a legislative instrument. The district located on longitude $0^{\circ} 3^{\prime}$ $25^{\prime \prime} \mathrm{E}$ and latitude $5^{\circ} 41^{\prime} 23^{\prime \prime} \mathrm{N}$ along the coastal belt of Tema, about $38 \mathrm{~km}$ from Accra, the capital of Ghana, is made up of five sub-districts. The sub-districts are Kpone (the district capital), Zenu, Gbetsile, Oyibi and Appolonia. Kpone-Katamanso has a huge population of about 109,864 inhabitants with several health facilities that are equitably distributed [25]. As at 2010, the district had about 736 health professionals working in its health facilities [25].

\section{Inclusion/exclusion criteria}

Health professionals with at least 1 year of experience at various health facilities, who interact directly with patients in relation to medicine use and are in a position to detect and report ADRs and also gave consent for participation were enrolled. Workers in the facilities who were solely employed for administrative duties and health workers on in-service or pre-qualification training were not included in this study.

\section{Sample size determination}

The sample size was estimated using the Cochran formula [26], with an assumption that $16 \%$ of health professionals have ever reported adverse drug reaction. This assumption is based on a similar study conducted by Sabblah et al., which found that $16 \%$ of health professionals in the Volta region of Ghana reported an ADR [17], with 95\% confidence interval (CI), 5\% precision and $15 \%$ non-response rate. The final sample size was 245 , representing the minimum number of participants required for this study. In all, a total of 363 professionals from 29 medical facilities as well as 34 community pharmacies in the District satisfied the inclusion criteria.

\section{Sampling technique}

Health professionals were selected by multistage random sampling. A list of all health facilities in the various subdistricts was obtained from the Kpone Katamanso District Health Directorate. There were 29 medical facilities in the District comprising six health centers, nine clinics, one polyclinic, one maternal home, seven hospitals and four CHPS. Also, there were 34 community pharmacies in the District. At the first stage of sampling, the 29 medical facilities were numbered and 19 were randomly selected. Again, the 34 community pharmacies were numbered and 17 community pharmacies were 
randomly selected using an online random number generator with permission from the authorities of these facilities. A total of 363 participants met the inclusion criteria for this study. However, after simple random sampling, where the eligible health professionals were made to pick from an envelope containing 800 shuffled sheets with equal proportions of 'Yes' and 'No" written on them. This random sampling technique was adopted from Arora et al. [27]. The randomly selected participants were informed on the rationale, ethical issues, and purpose of the study. They were also assured of privacy and confidentiality. Participants were permitted to ask questions. Informed consent was obtained from all the randomly selected participants before they were enrolled into the study.

\section{Data collection and management}

The data were collected using a closed-ended questionnaire developed after reviewing related studies and previous practice experience. The questionnaire captured the health professionals' demographics, knowledge of health professionals on spontaneous reporting, the attitude of health professionals towards reporting, ADR reporting practice, and the factors that they perceived may influence reporting. Provision was also made for suggestions on possible ways to improve ADR reporting. The dependent variable, Spontaneous of ADR, was measured as a 4-item composite variable. These items were; having observed a patient with an adverse reaction, reported adverse drug reaction, stated reporting of ADR to Food and Drugs Authority (FDA), having received a feedback from the FDA and documented the observed ADR. A score of 1 was awarded to each correct item. A Health professional was said to have reported an ADR if the respondent had ever witnessed an ADR, reported to FDA, since they are responsible for pharmacovigilance in Ghana and had received a feedback from FDA as stipulated in the FDA's Druglens Newsletter (10) or had documented the ADR as required by practice that health professionals should document clinical activities at all times. Hence, a score equal to or more than three means the participant had reported ADR before.

The proportion of health professionals who spontaneously reported an ADR was determined by dividing participants who had ever reported ADR by the number of participants assessed. To measure knowledge of participants, 6 items were used and every correct answer was coded as 1 , otherwise 0 for a wrong answer. A score of 5 to 6 was considered as Excellent 4 to 3 was Adequate, and 2 to 0 was rated as Poor knowledge of a participant on adverse drug reporting. The variable, knowledge was measured as an ordinal one. To measure attitude of professionals as poor or good, 12 items were used. A coding of 1 was scored for ticking Yes and 0 for ticking No. Attitude was classified as poor, if the respondent' scored a value greater than or equal to 6 whilst it was classified as good if the respondent scored a value less than 6. The factors affecting ADR reporting among community pharmacists were assessed based on multiple responses to questions like Concern that the ADR report may be wrong, availability of reporting forms, fear of legal consequences, the workload on participants, etc. These factors were coded 1 for Yes and 0 for No. This provided nominal variables, which were used for the univariate analysis. Data collected were checked, cleaned, coded and entered into Stata version 15 . The data were verified independently for errors and accuracy.

The researcher of this study encrypted the dataset with password protection and securely stored a copy of the dataset on a study designated pendrive kept in a safe. The paper questionnaires were shredded after the data were locked and securely stored on the pendrive.

\section{Data processing and analysis}

Descriptive statistics were used to summarise the sociodemographic characteristics of the study participants. Categorical variables were summarised using frequencies and percentages. A simple logistic regression analysis was carried out to determine the association between the dependent variable (spontaneous reporting of ADR) and the independent variables (unadjusted odds ratio). Multiple logistic regression analysis was then used to assess the association between variables that showed to be statistically significant under the Chi-square test and simple logistic regression analysis. The estimates were expressed with their respective 95\% Confidence Intervals (CIs) and $p$-values. A $p$-value $<0.05$ was considered statistically significant.

\section{Ethical considerations}

Ethical approval for the study was obtained from the Ghana Health Service Ethics Committee (Reference GHS-ERC032/01/18). Informed consent was obtained from the participants of the study. The researchers ensured that all health professionals were adequately educated on the purpose of the study, risks and benefits of the conduct of the study and the health professionals were allowed to ask questions before their consent was taken. The health professionals were assured of The confidentiality and privacy during the conduct of the study. The study procedures were carried out in accordance with relevant guidelines and regulations. 


\section{Results}

Demographic characteristics of participants

All 268 health professionals (Table 1) enrolled in the study responded to the questionnaire, giving a response rate of $100 \%$. There were $119(44.4 \%)$ males and 149 (55.6\%) females. The representation of the different professionals involved in the study sample were: 35 Medical Officers (13.1\%), 21 Pharmacists (7.8\%), 53 Pharmacy Technician (19.8\%), 93 Nurses (34.7\%), 31 midwives (11.6\%), 32 Physician Assistants (11.9\%) and 3 Disease Control Officers (1.1\%), and the average age was 34.1 $(\mathrm{SD}=0.47)$. The oldest age recorded among the 268 participants was 60 years, and the youngest was 20 years. The least experienced had a one-year record of practice, and the most experienced had 36 years of practice; the average years of practice of respondents was $8.5(\mathrm{SD}=$ 0.62). From the data collected, 208 (77.6\%) of the health professionals in the District had observed at least one case of ADR, whereas only 36 (17.3\%) had ever reported an ADR to the Ghana FDA. Of the 268 participants, 46 (17.1\%) had poor knowledge, 139 (51.9\%) had average knowledge, and 83 (31.0\%) had good knowledge of spontaneous reporting of ADR.

\section{Factors influencing spontaneous reporting of ADR}

Table 2 presents the results of the simple logistic regression models, showing the factors associated with spontaneous reporting of ADR. Age was independently significantly associated with spontaneous reporting of ADR. It was realized that health professionals who were more than 50 years old were 8.8 times more likely to report an adverse event compared to professionals who were less than 30 years old (Crude Odds Ratio [COR] = 8.75; $\mathrm{CI}=2.27-33.67$ ). The field of Health Profession was also found to be independently associated with the spontaneous reporting of ADR. Nurses were found to be $84 \%$ less likely to report an adverse event compared to medical doctors $(\mathrm{COR}=0.16 ; \mathrm{CI}=0.05-0.53)$. Pharmacy technicians were also 9.1 times less likely to report an adverse event compared to Medical Doctors $(\mathrm{COR}=$ 0.11 ; $C I=0.02-0.56)$. The level of knowledge of health professionals was significantly associated with Spontaneous Reporting of ADR. Health professionals with Excellent Knowledge of Spontaneous ADR reporting are 14.2 times more likely to report an $\mathrm{ADR}(\mathrm{COR}=14.17$; $\mathrm{CI}=$ 1.83-109.67). Under professional attitudes, it was realized that Health professionals who are Uncertain about the cause of ADR were $68 \%$ less likely to report an adverse event compared to professionals who are certain of an $\operatorname{ADR}(\mathrm{COR}=0.32 ; \mathrm{CI}=0.15-0.70)$. Health professionals who had inadequate time at work were 4.3 times less likely to report an ADR compared to health professionals who had adequate time $(\mathrm{COR}=0.23$; $\mathrm{CI}=0.11-$ 0.48). Health professionals who were afraid of Legal
Table 1 Socio-demographic Characteristics of Health professionals from Kpone-Katamanso District, Ghana

\begin{tabular}{|c|c|c|c|}
\hline Background Characteristics & Mean, (SD) & Number & Percentage (\%) \\
\hline \multicolumn{4}{|l|}{ Gender } \\
\hline Male & & 119 & 44.4 \\
\hline Female & & 149 & 55.6 \\
\hline \multicolumn{4}{|l|}{ Age (years) } \\
\hline Less than 30 & & 76 & 28.36 \\
\hline $30-39$ & $34.13,(0.472)$ & 139 & 51.87 \\
\hline $40-49$ & & 39 & 14.55 \\
\hline $50-59$ & & 8 & 2.99 \\
\hline Greater than 59 & & 6 & 2.24 \\
\hline \multicolumn{4}{|l|}{ Profession } \\
\hline Medical Officer & & 35 & 13.06 \\
\hline Pharmacist & & 21 & 7.84 \\
\hline Nurse & & 93 & 34.7 \\
\hline Pharm Tech & & 53 & 19.78 \\
\hline Midwife & & 31 & 11.57 \\
\hline Physician Assistant & & 32 & 11.94 \\
\hline Disease Control Officer & & 3 & 1.12 \\
\hline \multicolumn{4}{|l|}{ Institution } \\
\hline Government & & 88 & 32.84 \\
\hline Private Hospital & & 167 & 62.31 \\
\hline Community Pharmacy & & 13 & 4.85 \\
\hline \multicolumn{4}{|l|}{ Religion } \\
\hline Christian & & 234 & 87.97 \\
\hline Muslim & & 25 & 9.13 \\
\hline Other & & 8 & 3.01 \\
\hline \multicolumn{4}{|l|}{ Years of Practice } \\
\hline Less than 10 & & 194 & 72.39 \\
\hline $10-19$ & & 50 & 18.66 \\
\hline $20-29$ & & 18 & 6.72 \\
\hline Greater or equal to 30 & & 6 & 2.24 \\
\hline \multicolumn{4}{|l|}{ Marital Status } \\
\hline Married & & 165 & 61.57 \\
\hline Single & & 87 & 32.46 \\
\hline Divorced & & 16 & 5.97 \\
\hline \multicolumn{4}{|l|}{ Witnessed a case of ADR } \\
\hline Yes & & 208 & 77.61 \\
\hline No & & 60 & 22.39 \\
\hline \multicolumn{4}{|l|}{ Spontaneous Reporting } \\
\hline Yes & & 36 & 13.43 \\
\hline No & & 232 & 86.57 \\
\hline
\end{tabular}


Table 2 Simple logistic regression of spontaneous adverse event reporting and related factors

\begin{tabular}{|c|c|}
\hline VARIABLES & COR, $95 \% \mathrm{Cl}$ \\
\hline \multicolumn{2}{|l|}{ Socio-Demographic } \\
\hline \multicolumn{2}{|l|}{ Sex } \\
\hline Male & 1 \\
\hline Female & $0.77,(0.38-1.56)$ \\
\hline \multicolumn{2}{|l|}{ Age (years) } \\
\hline Less than 30 & 1 \\
\hline $30-39$ & 1.63, $(0.61-4.31)$ \\
\hline $40-49$ & $2.55,(0.79-8.21)$ \\
\hline Greater than 50 & $8.75,(2.27-33.67)^{a}$ \\
\hline \multicolumn{2}{|l|}{ Profession } \\
\hline Medical Officer & 1 \\
\hline Pharmacist & $2.17,(0.69-6.84)$ \\
\hline Nurse & $0.16,(0.05-0.53)^{\mathrm{a}}$ \\
\hline Pharm Tech & $0.11,(0.02-0.56)^{\mathrm{a}}$ \\
\hline Midwife & $0.69,(0.22-2.23)$ \\
\hline Physician Assistant & $0.30,(0.07-1.22)$ \\
\hline D. Control Officer & $5.78,(0.47-71.62)$ \\
\hline \multicolumn{2}{|l|}{ Institution } \\
\hline Government & 1 \\
\hline Private Hospital & $1.23,(0.58-2.64)$ \\
\hline Community Pharmacy & $0.54,(0.06-4.53)$ \\
\hline \multicolumn{2}{|l|}{ Religion } \\
\hline Christian & N/A \\
\hline Muslim & 0 \\
\hline Other & 0 \\
\hline \multicolumn{2}{|l|}{ Knowledge } \\
\hline Poor & 1 \\
\hline Average & $6.16,(0.80-47.8)$ \\
\hline Good & $14.17,(1.83-109.67)^{\mathrm{a}}$ \\
\hline VARIABLES & COR, 95\% Cl \\
\hline \multicolumn{2}{|l|}{ Professional Attitudes } \\
\hline \multicolumn{2}{|c|}{ Uncertainty about cause of ADR } \\
\hline No & 1 \\
\hline Yes & $0.32,(0.15-0.70)^{\mathrm{a}}$ \\
\hline \multicolumn{2}{|l|}{ Lack of Adequate time } \\
\hline No & 1 \\
\hline Yes & $0.23,(0.11-0.48)^{\mathrm{a}}$ \\
\hline \multicolumn{2}{|c|}{ Diffident about ADR occurrence } \\
\hline No & 1 \\
\hline Yes & $0.71,(0.34-1.49)$ \\
\hline \multicolumn{2}{|l|}{ Fear of legal repercussions } \\
\hline No & 1 \\
\hline Yes & $0.16,(0.06-0.37)^{a}$ \\
\hline \multicolumn{2}{|l|}{ Extraneous work } \\
\hline No & 1 \\
\hline Yes & $1.20,(0.55-2.54)$ \\
\hline
\end{tabular}

Table 2 Simple logistic regression of spontaneous adverse event reporting and related factors (Continued)

\begin{tabular}{ll}
\hline VARIABLES & COR, 95\% CI \\
\hline Ambitious to publish a case report & 1 \\
No & $0.62,(0.27-1.43)$ \\
Yes & \\
Mistrust in PV system & 1 \\
No & $0.56,(0.27-1.13)$ \\
Yes & \\
Negligence & 1 \\
No & $1.0,(0.49-2.03)$ \\
Yes & \\
Diffident about Procedure & 1 \\
No & 1
\end{tabular}

Yes

$0.29,(0.14-0.62)^{a}$

Indifferent about reporting

No

1

Yes

$1.87(0.87-4.0)$

Lack of incentives

No

Yes

$0.94,(0.46-1.94)$

Form of ADR reactions

Seriousness of reaction

No

Yes

N/A

Unusual reaction

No

1

Yes

$1.63(0.78-3.40)$

Unknown Reaction to product

No

Yes

$0.95(0.47-1.92)$

Stakeholder Factor

Unavailability of reporting forms

No

Yes

$0.21(0.09-0.48)^{a}$

Prompt Feedback

No

1

Yes

$2.38(1.13-4.98)^{a}$

$P V$ in curriculum

No

1

Yes

$1.10(0.53-2.26)$

Post-professional PV Training

No

$19.04(7.07-51.27)^{a}$

${ }^{\mathrm{a}}$ Statistically significant

COR Crude Odds Ratio

$\mathrm{Cl}$ Confidence interval

consequences after reporting an ADR were found to be 84\% less likely to report an ADR. Compared to health professionals who were not afraid of any legal 
consequences $\quad(\mathrm{COR}=0.16 ; \quad \mathrm{CI}=0.06-0.37) . \quad$ Lastly, under the health professional's attitude, it was found that health professionals who are diffident of the reporting procedure were $71 \%$ less likely to report an ADR compared to health professionals who are not diffident about the ADR reporting procedure $(\mathrm{COR}=0.29 ; \mathrm{CI}=0.14$ 0.62). Under the stakeholder's factors, health professionals who were not aware of the availability of reporting form were $79 \%$ less likely to report an ADR compared to health professionals who were aware of the availability of the reporting form $(\mathrm{COR}=0.21 ; \mathrm{CI}=$ 0.09-0.48). Health professionals who receive Prompt feedback from the FDA are 2.4 more likely to report an ADR compared to health professionals who do not receive $(\mathrm{COR}=2.38 ; \mathrm{CI}=1.38-4.98)$, and health professionals who received Pharmacovigilance training were 19 times more likely to report an ADR compared to health professionals who did not receive any Pharmacovigilance training $(\mathrm{COR}=19.04 ; \mathrm{CI}=7.07-51.27)$.

Table 3 presents the results of the multivariate logistic regression models, showing the factors associated with spontaneous reporting of ADR. After adjustment on potential confounding variables (Knowledge, Feedback from FDA, Uncertainty about cause of ADR, Severity of ADR), Age: $40-49$ (AOR $=93.10, p$-value $<0.01)$, Reporting by Nurses $(\mathrm{AOR}=0.01$, p-value $<0.01)$, the spontaneous reporting of ADR by Disease control officers $(\mathrm{AOR}=12.38$, $\mathrm{p}$-value $=0.02)$; Professional attitudes such as Uncertainty about $A D R$ report $(A O R=2.29$, pvalue $<0.01)$, No time for reporting $(\mathrm{AOR}=0.3$, $\mathrm{p}$ value $=0.03$ ), Fear of legal consequences after reporting $(\mathrm{AOR}=0.15$, $\mathrm{p}$-value $<0.01)$ and Post qualification training $(\mathrm{AOR}=18.78, \mathrm{p}$-value $<0.01)$; were statistically significant.

Figure 2 represents suggested forms of feedback that could improve spontaneous reporting of adverse drug reaction by the Health professionals of KponeKatamanso District. From the figure, 66.29\% of respondents suggested that the Food and Drugs Authority produce regular reports on recent Adverse Drug Reactions. In addition, $61.36 \%$ of the 268 respondents believed that Regular Pharmacovigilance Awareness reports and programs could help improve the spontaneous reporting rate of Adverse Drug Reaction. Some respondents (54.17\%) believed that individual feedback by the Ghana FDA to ADR reporting could go a long way to enhance reporting of ADR. 26.89\% suggested that annual statistic charts of cases of Adverse Drug Reactions would improve the feedback from the Ghana FDA, while 25.76\% of respondents would prefer a Global Drug Safety reports as feedback from the Food and Drugs Authority.

On recommended ways to improve Spontaneous Reporting, most of the respondents (70.08\%) recommended that there be awareness creation and sensitization through media. $62.88 \%$ of the respondents also believe that establishing Institutional Reporting Centres would improve ADR reporting rate. 53.78\% of respondents recommended Continuous Professional Education and Training. About a third of professionals (36.74\%) believe that the availability of reporting forms is integral for improving spontaneous reporting of adverse drug reaction. $28.03 \%$ of the respondents recommended that pharmacovigilance studies be incorporated into their educational curriculum (Fig. 3).

\section{Discussion}

The contribution of healthcare providers in reporting ADR is paramount to the sustenance of every pharmacovigilance system. This study provides germane insight regarding knowledge, practice and impetus of health professionals towards ADR reporting as well as its associated factors. This study revealed that only $36(17.3 \%)$ out of 208 health professionals who had witnessed an ADR in the Kpone-Katamanso District had ever spontaneously reported it to the Ghana FDA.

Assessing the factors that may influence the abysmal spontaneous reporting of ADR amongst health professionals in the District divulged that the age of health professionals is significantly associated with reporting ADR. Health professionals aged between 30 and 39 were 10.13 times more likely to report an ADR spontaneously than professionals younger than 30 years. In addition, professionals aged between 40 and 49 years are 93.10 times more likely to report an adverse drug reaction than professionals younger than 30 years. It may be implied that as health professionals get older, they tend to gain more experienced and are often conversant with reporting procedures.

A factor that could be accounting for the low reporting of ADR, as deduced from this study, is the availability of ADR reporting forms. Health professionals who do not have access to reporting forms are 3.6 times less likely to report an ADR compared to their counterparts with reporting forms available at their health facilities. This finding is consistent with that of Eweuko, which indicated that lack of reporting forms at the various health facilities hampered the rate of spontaneous reporting of adverse drug reactions among health professionals [28].

Time constraint was identified as a factor hindering Spontaneous reporting of ADR [12, 13]. The Annual fact and figures Statistical Report of Ghana reveals a low health professional to patient ratio implying an increase in job demand on health professionals [29]. It was observed that health professionals who complained of time constraint were 6.7 times less likely to report an ADR than those who did not complain of time constraint. Professionals should be educated on the relevance of spontaneous ADR reporting in ensuring safe medicines 
Table 3 Multivariate logistic regression of spontaneous adverse event reporting and related factors

\begin{tabular}{|c|c|c|c|}
\hline VARIABLE & Adj. Odd ratio & $95 \% \mathrm{Cl}$ & $P$ value \\
\hline \multicolumn{4}{|l|}{ Age (years) } \\
\hline Less than 30 (Ref) & 1 & & \\
\hline $30-39$ & 10.13 & $1.056-97.217$ & 0.045 \\
\hline $40-49$ & 93.10 & $4.577-1893.7$ & $0.003^{a}$ \\
\hline Greater than 50 & 2.21 & $0.0925-52.947$ & 0.624 \\
\hline \multicolumn{4}{|l|}{ Profession } \\
\hline Medical Officer (Ref) & 1 & & \\
\hline Pharmacist & 1.93 & $0.086-43.16$ & 0.67 \\
\hline Nurse & 0.01 & $0.001-0.185$ & $<0.01^{\mathrm{a}}$ \\
\hline Pharm Tech & 0.18 & $0.008-4.170$ & 0.29 \\
\hline Midwife & 3.31 & $0.161-67.852$ & 0.43 \\
\hline Physician Assistant & .20 & $0.0073-5.152$ & 0.32 \\
\hline Disease Control Officer & 12.382 & $1.8039-84.984$ & $0.02^{\mathrm{a}}$ \\
\hline \multicolumn{4}{|l|}{ Knowledge of Professionals } \\
\hline Poor (Ref) & 1 & & \\
\hline Average & 7.967 & $0.335-189.246$ & 0.2 \\
\hline Good & 8.311 & $0.333-207.123$ & 0.2 \\
\hline \multicolumn{4}{|c|}{ Uncertainty about cause of ADR } \\
\hline No (Ref) & 1 & & \\
\hline Yes & 0.34 & $0.11-1.06$ & 0.06 \\
\hline \multicolumn{4}{|c|}{ Time constraint to report ADR } \\
\hline No (Ref) & 1 & & \\
\hline Yes & 0.30 & $0.10-0.91$ & $0.03^{\mathrm{a}}$ \\
\hline \multicolumn{4}{|l|}{ Fear of legal repercussions } \\
\hline No (Ref) & 1 & & \\
\hline Yes & 0.15 & $0.41-0.51$ & $<0.01^{\mathrm{a}}$ \\
\hline \multicolumn{4}{|c|}{ Diffident about reporting procedure } \\
\hline No (Ref) & 1 & & \\
\hline Yes & 0.77 & $0.26-2.33$ & 0.65 \\
\hline \multicolumn{4}{|c|}{ Unavailability of Reporting form } \\
\hline No (Ref) & 1 & & \\
\hline Yes & 0.28 & $0.09-0.88$ & $0.03^{\mathrm{a}}$ \\
\hline \multicolumn{4}{|l|}{ Feedback from FDA } \\
\hline No (Ref) & 1 & & \\
\hline Yes & 2.12 & $0.70-6.37$ & 0.181 \\
\hline \multicolumn{4}{|l|}{ Pharmacovigilance training } \\
\hline No (Ref) & 1 & & \\
\hline Yes & 18.78 & $5.46-64.59$ & $<0.01^{\mathrm{a}}$ \\
\hline
\end{tabular}

Statistically Significant

AORAdjusted Odds Ratio

for the management of conditions. Regardless of the workload on professionals, they should be educated to view spontaneous reporting with equal importance in ensuring proper patient care. This is because a single report of an ADR may save numerous lives.

A significant proportion of Health Professionals attributed the hesitation in reporting ADR to fear of legal repercussions similar findings were reported in other studies [30]. Perception of professional error seems to be a major cause of this fear. Health Professionals are scared that they may be prosecuted if ADR experienced are due to administering the wrong drug or wrong diagnosis. After reporting an ADR, assurance of legal protection would go a long way to increase reporting amongst Healthcare providers provided due procedures were adhered to. In addition, stakeholders should assure reporters of confidentiality and anonymity in order to boost the ADR reporting rate.

The study found that training on pharmacovigilance improves ADR reporting as health professionals who received some form of training on pharmacovigilance were 5.5 times more likely to report an adverse reaction than those with no training on pharmacovigilance. Pharmacovigilance training was significantly associated with spontaneous reporting of ADR. These findings are consistent with that of Sabblah et al. [17], who also concluded that professionals' post-professional training positively impacted spontaneous reporting rates. It has been realized that healthcare professionals' pharmacovigilance training and education is one of the strategies proposed to increase ADR reporting rates [17].

Low rates of feedback from authorities on submitted ADR forms could account for health professionals' lackadaisical attitude to reporting of ADR. A study by Toklu et al. [31] disclosed that nearly $80 \%$ of pharmacists in Cyprus strongly approve that feedback to reports received from the National Pharmacovigilance Centre will go a long way to motivate them to report adverse drug reactions. It was imperative to find out from the respondent's opinions on which forms of feedback would motivate them to report an adverse drug reaction. More than half of respondents from this study suggested that the Ghana FDA produce a regular newsletter on recent ADR. Yearly, the Ghana FDA releases a newsletter called the Druglens, which seeks to inform health professionals on strides made in the area of spontaneous reporting. These newsletters are disseminated to the various health facilities and made accessible to all health professionals. However, a survey by the FDA revealed that $38.3 \%$ of Health professionals were aware of at least one of the letters distributed to all professionals in 2013 [24]. This finding indicates that most professionals are not aware of any news alert on ADR and other relevant information to improve spontaneous reporting of ADR.

On recommended ways to improve Spontaneous ADR Reporting, studies have shown a paucity of empirical data on pharmacovigilance awareness in Africa [32]. 


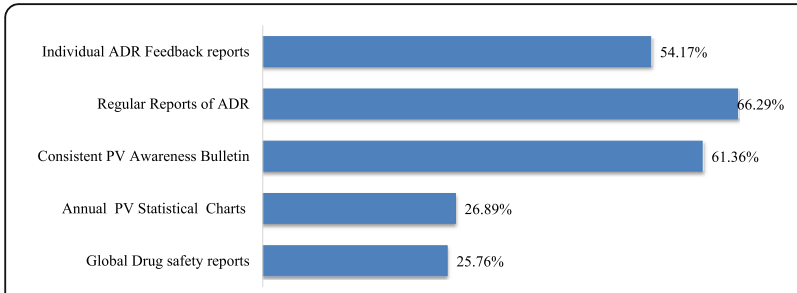

Fig. 2 Expected Forms of Feedback from Pharmacovigilance System

Therefore, it is not surprising that most of the respondent $(70.1 \%)$ recommended that there be sensitization on ADR reporting through media on the need for health professionals to report ADR. This recommendation is very laudable because sensitization through the media encourages reporting among consumers. Sometimes, especially at the community pharmacy, professionals depend on reports received from consumers to report an ADR. Nwokike \& Eghan recommended media publicity following a review of Ghana's pharmacovigilance system [33]. If these reports are not received or are lacking in vital information for assessments, it negatively affects the professional's ability to report adverse drug reaction.

Over $50 \%$ of the respondents also believe that establishing ADR Reporting Centers at the various health facilities would improve the ADR reporting rate (Fig. 3). The Ghana FDA has introduced Institutional Contact Person (ICP) on pharmacovigilance who may be health professionals serving as a liaison between the Ghana FDA and the health professionals at the various institutions. This is a measure to improve spontaneous reporting of ADR among health professionals. Health professionals are now able to report ADR directly to the ICP. Nonetheless, there should be Institutional Reporting Centers (IRC), which the ICP could head. This would increase professionals' awareness of the need to report ADR. It would also reduce the fear of legal repercussions after reporting since professionals who report are guaranteed anonymity and confidentially from the regulators (FDA).

A proportion of $53.78 \%$ of respondents recommended Continuous Professional Education and Training to be a sure way of improving spontaneous reporting of ADR.

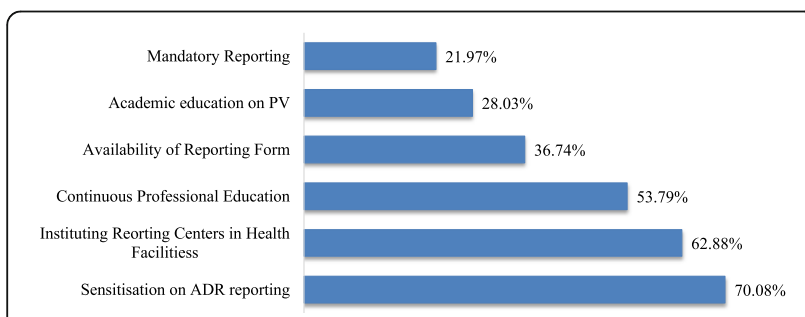

Fig. 3 Recommended Ways to improve ADR Among Health Professionals
Continuous Professional Development (CPD) can be very beneficial for one's career. Undertaking a CPD programme is a mandatory requirement for some professionals. It helps by advancing the knowledge and skills; professionals need to be confident that they are working at the top end of their profession. Pharmacovigilance training could be held during continuous professional development programs to train professionals on spontaneous reporting. It also offers an appropriate platform to assure professionals that there is no legal liability for reporting an adverse reaction. Professionals would also get adequate opportunity to ask questions pertaining to the spontaneous reporting of ADR.

This study is subject to recall bias as some health professionals were unable to adequately remember whether they reported or documented the adverse drug reactions. The information obtained is subjective since some respondents may give false information to look good or be perceived as professionals.

\section{Conclusion}

Though most professionals demonstrated average knowledge on spontaneous reporting of ADR, the proportion of professionals who report ADR was low. The knowledge of professionals did not affect their attitude towards spontaneous reporting of adverse drug reaction. A policy should be implemented to make spontaneous reporting of adverse drug reaction mandatory for health professions. Just as it is stipulated in Section 125 of the Public Health Act, 2012, Act 851, that manufacturers should mandatorily report adverse drug reaction [34].

Given the public health impact of adverse drug reaction, Regulators are called upon to intensify awareness through media sensitization and engagement of all relevant stakeholders on the need for the entire population to report adverse drug reactions they experience.

\section{Abbreviations}

ADR: Adverse Drug Reaction; CHPS: Community-based Health Planning Services; CPD: Continuous Professional Development; FDA: Food and Drugs Authority; GHS: Ghana Health Service; $\mathrm{MOH}$ : Ministry of Health;

IMU: International Monitoring Unit; ICP: Institutional Contact Person; IRC: Institutional Reporting Center; GHS: Ghana Health Service; QPPV: Qualified Person for Pharmacovigilance; WHO: World Health Organization

\section{Acknowledgements}

We acknowledge the efforts of Ronald Amoah Nsoh, Bright Osei, and Shadrach Darko of the Kpone Katamanso Health Directorate for their immense support during the conduct of the study.

\section{Authors' contributions}

MA and ADA conceived and designed the project. MA carried out data collection. PN, ND, and KOA provided technical support. MA performed data analyses. MA, KOA, PN, ND and ADA interpreted data for this study. MA, KOA $P N, N D$ and ADA drafted the work and revised it critically for important intellectual content. ADA supervised the study. All authors read and approved the final manuscript. 


\section{Funding}

Authors received no specific funding for this work.

\section{Availability of data and materials}

The dataset used and/or analyzed during the current study are available from the corresponding author on reasonable request.

\section{Declarations}

\section{Ethics approval and consent to participate}

Ethical approval for the study was obtained from the Ethical Review Committee of the Ghana Health Service (Reference - GHS-ERC032/01/18). The study procedures were carried out in accordance with relevant guidelines and regulations. Informed consent was obtained from all health professionals before enrolment in the study. Participants were guaranteed the right to be informed about the outcome of the study.

\section{Consent for publication}

Not applicable.

\section{Competing interests}

The authors declare that they have no competing interests.

\section{Author details \\ 'Department of Epidemiology and Disease Control, School of Public Health, College of Health Sciences, University of Ghana, Legon, Ghana. ${ }^{2}$ Department of Optometry and Visual Science, College of Science, Kwame Nkrumah University of Science and Technology, Kumasi, Ghana. ${ }^{3}$ Department of Pharmacy Practice, College of Health Sciences, Kwame Nkrumah University of Science and Technology, Kumasi, Ghana. ${ }^{4}$ University of Ghana Centre for Evidence Synthesis and Policy, School of Public Health, University of Ghana, Legon, Accra, Ghana.}

\section{Received: 19 April 2021 Accepted: 24 December 2021}

\section{Published online: 20 January 2022}

\section{References}

1. Alomar MJ. Factors affecting the development of adverse drug reactions (review article). Saudi Pharm J. 2014;22(2):83-94. https://doi.org/10.1016/j. jsps.2013.02.003

2. Edwards IR, Aronson JK. Adverse drug reactions: definitions, diagnosis, and management. Lancet. 2000;356(9237):1255-9. https://doi.org/10.1016/S01406736(00)02799-9.

3. Sultana J, Cutroneo P, Trifirò G. Clinical and economic burden of adverse drug reactions. J Pharmacol Pharmacother. 2013;4(Suppl 1):S73-7. https:// doi.org/10.4103/0976-500X.120957.

4. Goyal M, Bansal M, Yadav S, Grover V, Preetkanwal. to assess the attitude, knowledge and practices of medical professionals about adverse drug reactions and their reporting in a teaching hospital. Indian J Clinical Practice. 2013;24(3):281-4.

5. Suh D-C, Woodall B, Shin S, Santis E. Clinical and economic impact of adverse drug reactions in hospitalized patients. Ann Pharmacother. 2001; 34(12):1373-9. https://doi.org/10.1345/aph.10094.

6. Nadew SS, Beyene KGM, Beza SW. Adverse drug reaction reporting practice and associated factors among medical doctors in government hospitals in Addis Ababa, Ethiopia. PLoS One. 2020;15(1):e0227712. https://doi.org/10.13 71/journal.pone.0227712.

7. Martin K, Bégaud B, Latry P, Miremont-Salamé G, Fourrier A, Moore N. Differences between clinical trials and postmarketing use. $\mathrm{Br} J$ Clin Pharmacol. 2004;57(1):86-92. https://doi.org/10.1046/j.1365-2125.2003.01953. $x$.

8. Pal SN, Duncombe C, Falzon D, Olsson S. WHO strategy for collecting safety data in public health programmes: complementing spontaneous reporting systems. Drug Saf. 2013;36(2):75-81. https://doi.org/10.1007/s40264-0120014-6.

9. The safety of medicines in public healthprogrammes: pharmacovigilance an essential tool. [https://www.who.int/medicines/areas/quality_safety/safety_ efficacy/Pharmacovigilance_B.pdf?ua=1].

10. Drug Lense Newsletter Issue 8. [http://www.fdaghana.gov.gh/img/reports/ DrugLens\%20FINAL\%202020\%2D\%2D.pdf].
11. Tandon VR, Mahajan V, Khajuria V, Gillani Z. Under-reporting of adverse drug reactions: a challenge for pharmacovigilance in India. Indian J Pharm. 2015; 47(1):65-71. https://doi.org/10.4103/0253-7613.150344.

12. Appiasam-Dadson B, Amedome S. Pharmacovigilance practices: knowledge and attitudes among healthcare professionals at the Volta regional hospital of Ghana. J Pharm. 2017:05(03). https://doi.org/10.4172/2329-6887.1000229.

13. Inman W. Attitudes to adverse drug-reaction reporting. Br J Clin Pharmacol. 1996;41(5):433-5. https://doi.org/10.1111/j.1365-2125.1996.tb00040.x.

14. Yu YM, Lee E, Koo BS, Jeong KH, Choi KH, Kang LK, et al. Predictive factors of spontaneous reporting of adverse drug reactions among community pharmacists. PLoS One. 2016;11(5):e0155517. https://doi.org/10.1371/journal. pone.0155517.

15. Gurmesa LT, Dedefo MG. Factors affecting adverse drug reaction reporting of healthcare professionals and their knowledge, attitude, and practice towards ADR reporting in Nekemte town, West Ethiopia. Biomed Res Int. 2016;2016:5728462-6. https://doi.org/10.1155/2016/5728462.

16. Al-Hazmi N, Naylor I. Attitude and awareness of adverse drug reaction reporting by health professionals in seven hospitals in the Holy City of Makkah, Kingdom of Saudi Arabia. J Clin Trials. 2013;3(3):1-5. https://doi. org/10.4172/2167-0870.1000139.

17. Sabblah GT, Akweongo P, Darko D, Dodoo ANO, Sulley AM. Adverse drug reaction reporting by doctors in a developing country: a case study from Ghana. Ghana Med J. 2014;48(4):189-93. https://doi.org/10.4314/gmj.v48i4.4.

18. Kelly M, Kaye Kl, Davis SR, Shenfield GM. Factors influencing adverse drug reaction reporting in New South Wales teaching hospitals. J Pharm Pract Res. 2004;34(1):32-5. https://doi.org/10.1002/jppr200434132.

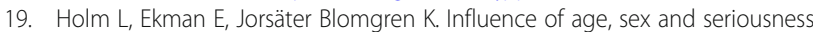
on reporting of adverse drug reactions in Sweden. Pharmacoepidemiol Drug Saf. 2017;26(3):335-43. https://doi.org/10.1002/pds.4155.

20. Duarte M, Ferreira P, Soares M, Cavaco A, Martins AP. Community pharmacists' attitudes towards adverse drug reaction reporting and their knowledge of the new pharmacovigilance legislation in the southern region of Portugal: a mixed methods study. Drugs Therapy Perspect. 2015; 31(9):316-22. https://doi.org/10.1007/s40267-015-0227-8.

21. Irujo M, Beitia G, Bes-Rastrollo M, Figueiras A, Hernández-Diaz S, Lasheras B. Factors that influence under-reporting of suspected adverse drug reactions among community pharmacists in a Spanish region. Drug Saf. 2007;30(11): 1073-82. https://doi.org/10.2165/00002018-200730110-00006.

22. Ozcan G, Aykac E, Kasap Y, Nemutlu NT, Sen E, Aydinkarahaliloglu ND. Adverse drug reaction reporting pattern in Turkey: analysis of the national database in the context of the first pharmacovigilance legislation. Drugs Real World Outcomes. 2016;3(1):33-43. https://doi.org/10.1007/s40801-0150054-1.

23. Strengthening Pharmaceutical Systems (SPS) Program. Indicator-based pharmacovigilance assessment tool: Manual for conducting assessments in developing countries. Submitted to the U.S. Agency for International Development by the SPS Program. [https://pdf.usaid.gov/pdf_docs/PNADS1 67.pdf].

24. DrugLens Newsletter Issue 4. [https://fdaghana.gov.gh/img/reports/ Druglens\%20lssue\%204\%202016_FINAL-min.pdf].

25. 2010 Population and housing census: District analytical report, Asuogyaman District. [https://www2.statsghana.gov.gh/docfiles/2010_District_Report/Ea stern/ASUOGYAMAN.pdf].

26. Cochran W. Sampling techniques. 3rd ed. Wiley: New York; 1977.

27. Arora V, Sharma R, Chowdhary S. Comparative evaluation of treatment effects between two fixed functional appliances for correction of class II malocclusion: a single-center, randomized controlled trial. Angle Orthod. 2018;88(3):259-66. https://doi.org/10.2319/071717-476.1.

28. Ezeuko AY, Ebenebe UE, Nnebue CC, Ugoji JO. Factors associated with the reporting of adverse drug reactions by health workers in nnewi Nigeria. Int J Prev Med. 2015;6(1):25. https://doi.org/10.4103/2008-7802.153862.

29. The Health Sector in Ghana Facts and Figures. [https://ghanahealthservice. org/downloads/Facts+Figures_2018.pdf].

30. Rhonda HG: Patient safety and quality: An evidence-based handbook for nurses. (Prepared with support from the Robert Wood Johnson Foundation). Rockville, MD: Agency for Healthcare Research and Quality: AHRQ Publication No. 08-0043.; 2008

31. Toklu H, Soyalan M, Gültekin O, Özpolat M, Aydin M, Günay A, et al. The knowledge and attitude of the healthcare professionals towards pharmacovigilance and adverse drug reaction reporting in northern Cyprus. J Pharm. 2016;04(01). https://doi.org/10.4172/2329-6887.1000193. 
32. Oshikoya KA, Awobusuyi JO. Perceptions of doctors to adverse drug reaction reporting in a teaching hospital in Lagos, Nigeria. BMC Clin Pharmacol. 2009;9(1):14. https://doi.org/10.1186/1472-6904-9-14.

33. Nwokike J, Eghan K. Pharmacovigilance in Ghana: a systems analysis. Submitted to the US Agency for international development by the strengthening pharmaceutical systems (SPS) program. Management Sciences for Health: Arlington; 2010.

34. Public Health Act 2012, Act 851 [http://extwprlegs1.fao.org/docs/pdf/gha13 6559.pdf].

\section{Publisher's Note}

Springer Nature remains neutral with regard to jurisdictional claims in published maps and institutional affiliations.

Ready to submit your research? Choose BMC and benefit from:

- fast, convenient online submission

- thorough peer review by experienced researchers in your field

- rapid publication on acceptance

- support for research data, including large and complex data types

- gold Open Access which fosters wider collaboration and increased citations

- maximum visibility for your research: over $100 \mathrm{M}$ website views per year

At $B M C$, research is always in progress.

Learn more biomedcentral.com/submissions 